\title{
Tocogram characteristics of uterine rupture: a systematic review
}

\author{
Marion W. C. Vlemminx ${ }^{1,2} \cdot$ Hinke de Lau $^{1,2} \cdot$ S. Guid Oei ${ }^{1,2}$
}

Received: 5 July 2016/ Accepted: 27 September 2016/Published online: 8 October 2016

(c) The Author(s) 2016. This article is published with open access at Springerlink.com

\begin{abstract}
Purpose Timely diagnosing a uterine rupture is challenging. Based on the pathophysiology of complete uterine wall separation, changes in uterine activity are expected. The primary objective is to identify tocogram characteristics associated with uterine rupture during trial of labor after cesarean section. The secondary objective is to compare the external tocodynamometer with intrauterine pressure catheters.

Methods MEDLINE, EMBASE, and the Cochrane library were systematically searched for eligible records. Moreover, clinical guidelines were screened. Studies analyzing tocogram characteristics of uterine rupture during trial of labor after cesarean section were appraised and included by two independent reviewers. Due to heterogeneity, a metaanalysis was only feasible for uterine hyperstimulation.

Results Thirteen studies were included. Three tocogram characteristics were associated with uterine rupture. (1) Hyperstimulation was more frequently observed compared with controls during the delivery (38 versus $21 \%$ and 58 versus $53 \%$ ), and in the last $2 \mathrm{~h}$ prior to birth (19 versus $4 \%)$. Results of meta-analysis: OR 1.68 (95\% CI $0.97-2.89), p=0.06$. (2) Decrease of uterine activity was observed in 14-40\% and (3) an increasing baseline in 10-20\%. Five studies documented no changes in uterine
\end{abstract}

Marion W. C. Vlemminx

marionvlemminx@hotmail.com;

marion.vlemminx@mumc.nl

1 Department of Obstetrics and Gynecology, Máxima Medical Center, P.O. Box 7777, 5500 MB Veldhoven,

The Netherlands

2 Department of Electrical Engineering, Eindhoven University of Technology, P.O. Box 513, 5600 MB Eindhoven, The Netherlands activity or Montevideo units. A direct comparison between external tocodynamometer and intrauterine pressure catheters was not feasible.

Conclusions Uterine rupture can be preceded or accompanied by several types of changes in uterine contractility, including hyperstimulation, reduced number of contractions, and increased or reduced baseline of the uterine tonus. While no typical pattern has been repeatedly reported, close follow-up of uterine contractility is advised and hyperstimulation should be prevented.

Keywords External tocodynamometer .

Hyperstimulation - Intra-uterine pressure catheter .

Tocogram - Trial of labor after cesarean section - Uterine rupture

$\begin{array}{ll}\text { Abbreviations } \\ \text { CS } & \text { Cesarean section } \\ \text { EHG } & \text { Electrohysterography } \\ \text { GA } & \text { Gestational age } \\ \text { IUPC } & \text { Intrauterine pressure catheter } \\ \text { MVU } & \text { Montevideo units } \\ \text { SVD } & \text { Spontaneous vaginal delivery } \\ \text { TOCO } & \text { External tocodynamometer } \\ \text { TOLAC } & \text { Trial of labor after previous cesarean section } \\ \text { VBAC } & \text { Vaginal birth after cesarean section }\end{array}$

\section{Introduction}

There is a worldwide increasing incidence of cesarean sections (CS) [1,2]. Subsequently, there will be a growing number of pregnant women with a previous uterine scar. The high success $(76 \%)$ of vaginal birth after cesarean section (VBAC) and the degree of maternal and neonatal 
safety have encouraged physicians and midwives to be supportive of women attempting trial of labor after the previous cesarean section (TOLAC) [3, 4]. Moreover, VBAC is advocated as a means to control the increasing rates of operative delivery [5]. Despite the excellent outcome, every physician should keep in mind the risk of a uterine rupture. Unfortunately, the incidence of uterine rupture has not declined in the last decades [6]. Women opting for TOLAC have a less than $1 \%$ chance on a complete uterine rupture, which is associated with an estimated $10 \%$ risk of perinatal mortality [4, 7-10].

The number of repeat CS needed to prevent one uterine rupture is very high [11]. Alternatively, intrapartum monitoring of women during TOLAC could be improved. The classical symptoms of uterine rupture are described as fetal heart rate abnormalities, the onset of severe abdominal pain persisting between contractions, scar tenderness, abnormal vaginal bleeding, hematuria, cessation of previously efficient uterine activity, loss of station of the presenting part, and maternal hypotension or shock [12]. Timely diagnosing a uterine rupture remains challenging as these symptoms can appear at a late stage or may not be present at all $[3,13-15]$. In the end, the diagnosis will have to be confirmed or rejected during an emergency CS.

Clinical guidelines concerning TOLAC mainly focus on fetal heart rate abnormalities and clinical signs [12, 16]. However, based on the pathophysiology of complete uterine wall separation, changes in the uterine activity can be expected. A defect in the uterine wall reduces wall tension and can, therefore, lead to a decrease or clipping of intrauterine pressure [17]. Moreover, reduced tension can diminish contractility and influence contraction frequency and/or amplitude [18]. Therefore, uterine activity patterns, monitored by an intrauterine pressure catheter (IUPC), external tocodynamometer (TOCO), or electrohysterogram (EHG) could potentially provide warning signs of uterine rupture [19].

This systematic review aims to summarize the tocographic characteristics related to uterine rupture during TOLAC. The primary goal is to identify changes in the tocogram preceding or occurring during this emergency event. The secondary goal is to compare TOCO with IUPC.

\section{Materials and methods}

\section{Sources}

This systematic review was conducted according to the PRISMA guidelines. The MEDLINE, EMBASE, and the Cochrane library have been systematically searched in September 2016 using the following standardized medical subject headings (MeSH): uterine rupture, obstetric labor, trial of labor, vaginal birth after cesarean, uterine contraction, uterine monitoring, fetal monitoring, cardiotocography, tocogram, and related terms presented in the title and abstract. No limits have been used. The full electronic search strategy is available in "Appendix". Furthermore, the references of paragraphs on intrapartum monitoring during TOLAC available in national and international guidelines (NVOG, ACOG, RCOG, and SOGC), as well as the references of the selected articles have been included. To assess eligibility of the studies, two authors (MV, HdL) independently appraised and cross checked the extracted studies. In case of disagreement, the two reviewers reconsidered the article and made the final decision.

\section{Study selection}

A total of 175 articles have been systematically identified after removing duplicates. Figure 1 shows a flowchart of the search strategy and selection. We selected studies that featured an analysis of the uterine activity during TOLAC, in term pregnant women with a complete uterine rupture confirmed during CS or during postpartum complications. In each study population, there should be a minimum of five cases and at least $50 \%$ of the women should have a previous cesarean scar. Articles not in English, case reports, reviews, and guidelines were excluded. Because of the limited amount of available evidence, the critical appraisal was restricted to study design, patient selection, and analysis of the tocogram. After reading the 46 full-text articles, the reviewers excluded two reports based on patient selection. Since a minority of the women had a previous CS, the case-control study of Sheiner et al. and the study of Chen et al. have been excluded [20, 21]. The quality of the articles was assessed using the NewcastleOttawa scale, which is a quality assessment tool for nonrandomized studies included in meta-analysis. This scale contains eight items, which are categorized into three themes: selection (four stars), comparability (two stars), and exposure (three stars) [22]. High-quality studies achieve seven stars or more, medium quality studies between four and six stars, and poor-quality studies less than four stars.

\section{Statistical analysis}

Data of all included studies have been extracted and subdivided into a variety of characteristics related to uterine rupture. If not provided, odds ratios and $95 \%$ confidence interval $(95 \% \mathrm{CI})$ were calculated using contingency tables when possible. A meta-analysis was only considered feasible for uterine hyperstimulation during delivery due to the heterogeneity of the included studies with regard to the study design and the observed tocogram characteristics. 


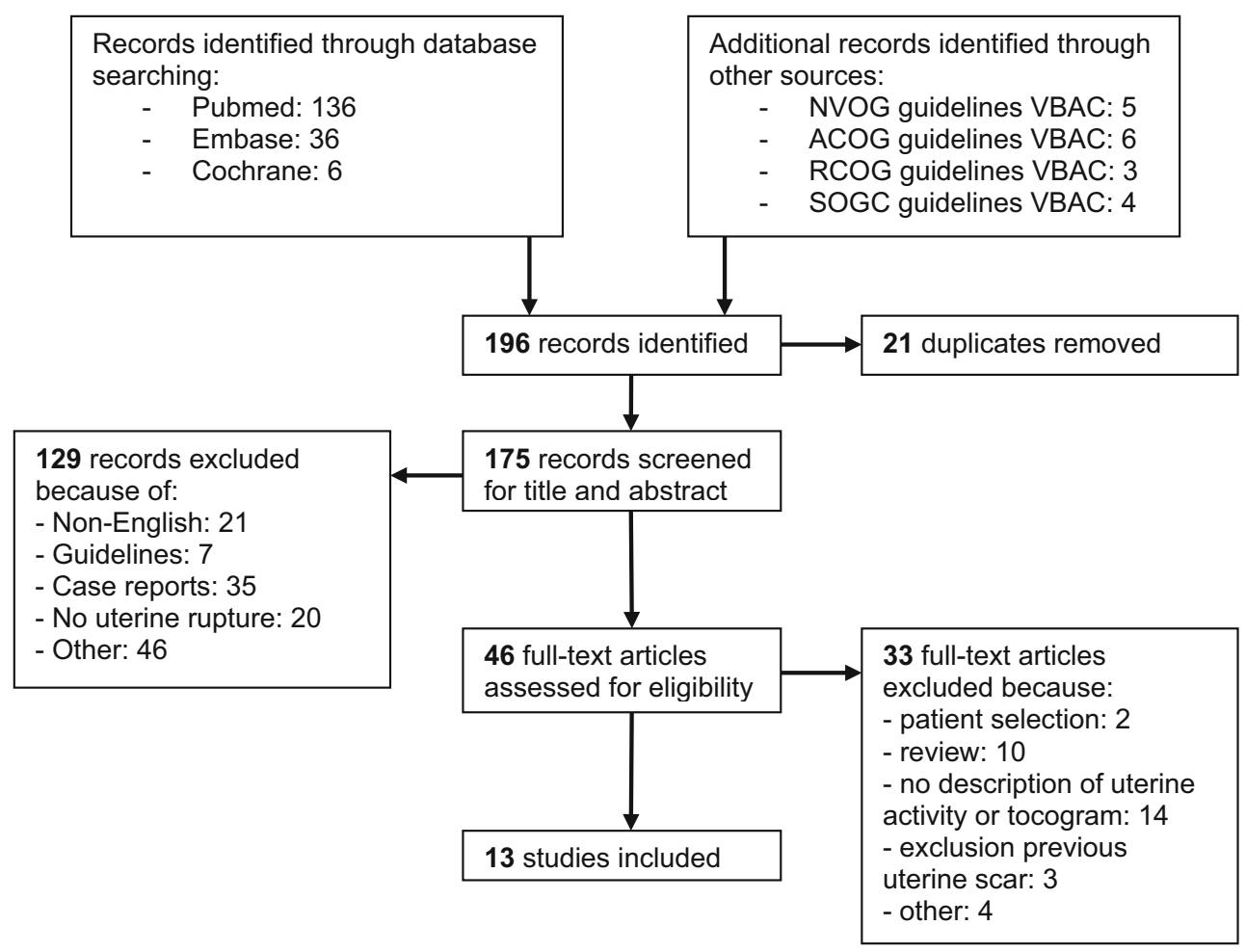

Fig. 1 Flowchart of the reviewing process

We performed the meta-analysis in RevMan (Revision Manager 5.3 for Windows, Utrecht; Cochrane The Netherlands) and applied a random effects model. Interstudies heterogeneity was tested using the Chi-squared test. A $p$ value of $<0.05$ was considered statistical significant.

\section{Results}

Thirteen studies have been included in this systematic review: one prospective cohort study, six case-control studies, and six retrospective cohort studies. The results could be categorized into five main themes: hyperstimulation, decrease in uterine activity, increased baseline, Montevideo units, or no changes in tocogram characteristics. An overview of the included studies and their results are shown in Table 1.

\section{Hyperstimulation}

The frequency of contractions prior to uterine rupture has been examined in three case-control studies. In the study by Goetzl et al., uterine rupture was more often preceded by an episode of hyperstimulation (defined as $>5$ contractions per $10 \mathrm{~min}$, that resulted in reduced administration of oxytocin) compared with controls: 37.5 and $20.8 \%$, $p=0.05$, which is on the margin of significance [23]. Odds ratios were not provided. Craver Pryor et al. studied hyperstimulation at more than $4,2-4$, and less than $2 \mathrm{~h}$ prior to delivery. Hyperstimulation (defined as $>5$ contractions per $10 \mathrm{~min}$ ) was more common during the $2 \mathrm{~h}$ prior to birth: 19.2 and $3.8 \%, p<0.05$ (OR 5.9, CI 1.2-28.6) [24]. In contrast, a more recent study of Andersen et al. showed no significant difference in uterine hyperstimulation ( $>5$ contractions per $10 \mathrm{~min}$ ) during labor: $58.5 \%$ in the rupture group versus $53.5 \%$ in controls, $p=0.74$ [25]. Subanalyses in the first/second stage and induced/augmented labor also showed no significant differences in their study. All three case-control studies did not report how the uterine activity patterns were monitored.

\section{Meta-analysis of hyperstimulation}

A meta-analysis was performed based on the three abovementioned case-control studies evaluating uterine hyperstimulation during TOLAC in relation to the risk of uterine rupture (see Fig. 2). Uterine hyperstimulation during TOLAC showed a trend in relation to the risk of uterine rupture: OR 1.68 (95 \% CI 0.97-2.89), $p=0.06$. The Chisquared test for inter-study heterogeneity was non-significant $(p=0.58)$.

\section{Decrease in uterine activity}

In a large nationwide Dutch prospective cohort study of Zwart et al., acute absence of contractions was reported in 


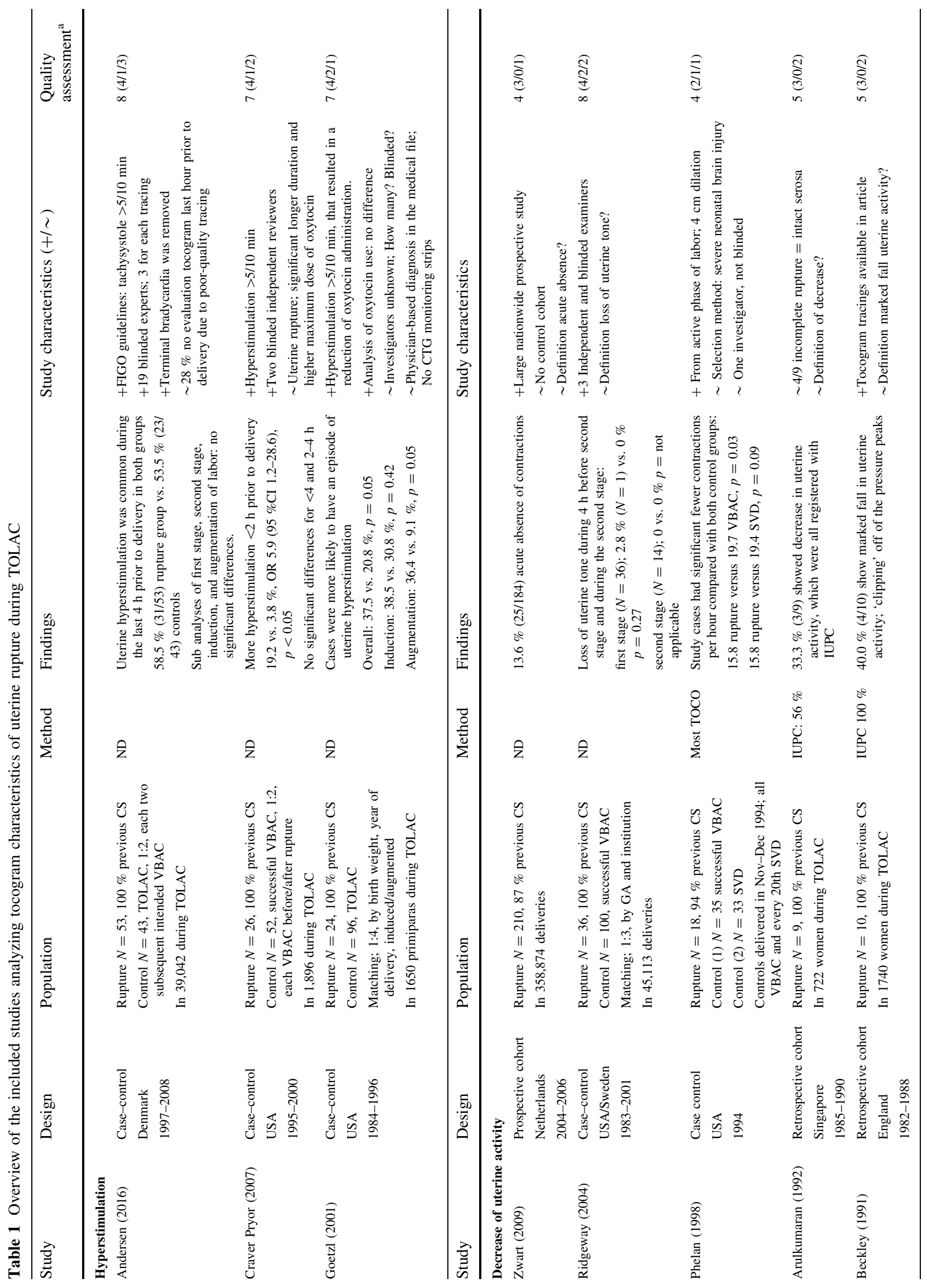




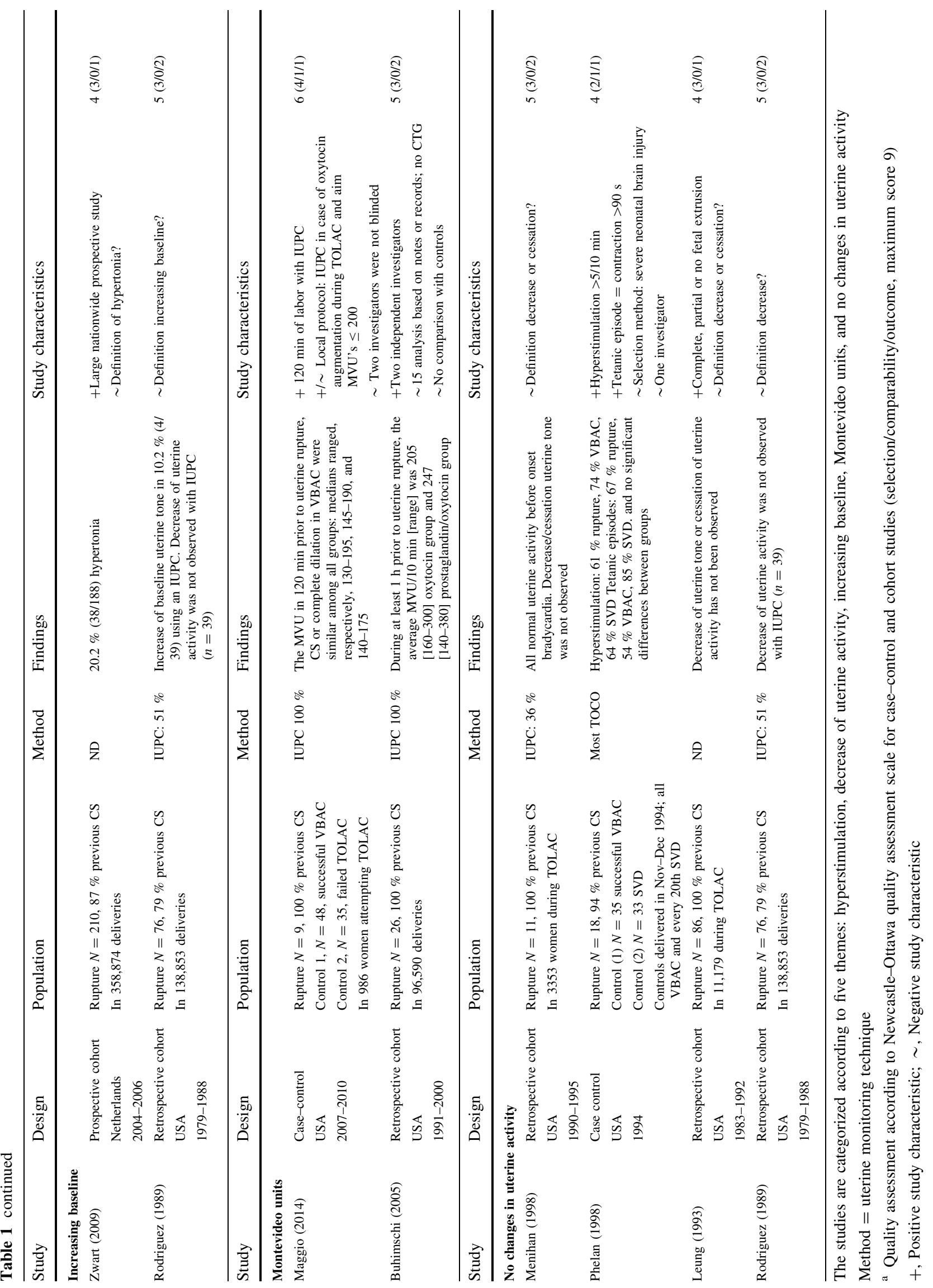




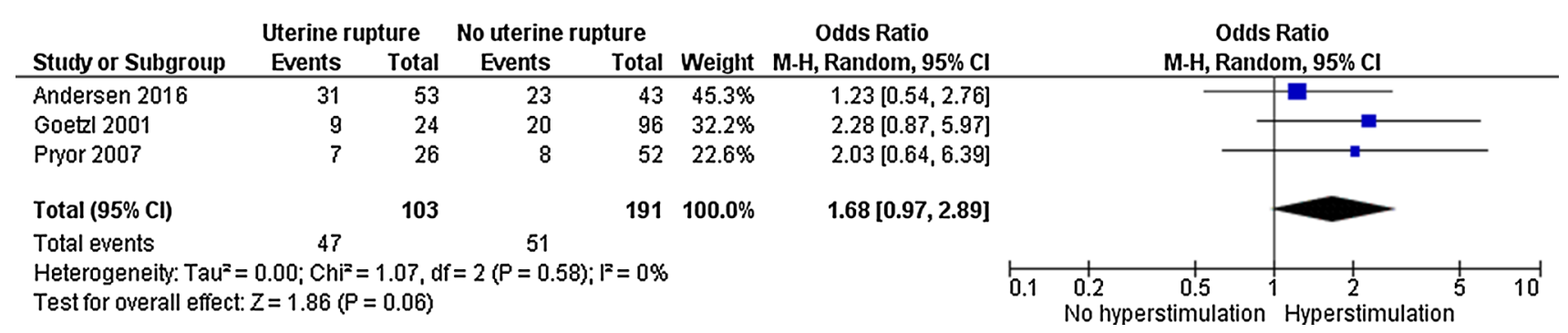

Fig. 2 Review: tocogram characteristics related to uterine rupture. Comparison: hyperstimulation and no hyperstimulation during trial of labor after the previous cesarean section. Outcome: risk of uterine rupture

$13.6 \%(25 / 184)$ of the cases of uterine rupture [10]. They did not describe the applied uterine monitoring techniques. A smaller case-control study of Ridgeway et al. focused on fetal heart rate characteristics of patients with uterine rupture compared with successful VBAC. They described loss of uterine tone during the first stage in a single case (1/ 36) [14]. Two small retrospective studies of Arulkumaran et al. and Beckley et al. found a decrease of the uterine contraction amplitude in, respectively, $33.3 \%$ (3/9) and $40.0 \%(4 / 10)$ of the uterine ruptures, which were all monitored by IUPC $[26,27]$. Finally, Phelan et al. observed a significantly $(p=0.03)$ lower amount of contractions per hour in ruptures $(15.8 / \mathrm{h})$ compared with $\operatorname{VBAC}(19.7 / \mathrm{h})$, monitored from the onset of active labor defined as cervical dilation of $4 \mathrm{~cm}$ [28]. This difference was not significantly different when comparing only oxytocin recipients; 16.5 contractions per hour in the rupture group, and 18.1 contractions per hour in VBAC. Most of their cases had external fetal monitoring.

\section{Increasing baseline}

Zwart et al. observed hypertonia in $20 \%$ (38/188) of the uterine ruptures in their large nationwide prospective study [10]. They did not describe their definition of hypertonia or which uterine monitoring technique (i.e., TOCO or IUPC) was applied. The retrospective study of Rodriguez et al. detected an increased baseline uterine pressure in $10 \%$ $(n=4)$ of the uterine rupture cases $(n=39)$ which were monitored with an IUPC [29].

\section{Montevideo units}

Montevideo units (MVU) can only be calculated in the presence of an IUPC. In the case-control study of Maggio et al., cases of uterine rupture have been compared with successful VBAC and failed TOLAC [35]. They found no association between MVU and uterine rupture in pregnant women undergoing TOLAC. Over time, MVU showed a continued increase during the last $2 \mathrm{~h}$ prior to birth in the successful VBAC group $(p<0.01)$ and lack of such increase in the rupture group $(p=0.26)$. However, when only using the first stage of labor, there was no difference in MVU over time between uterine rupture versus VBAC $(p=0.22)$ and uterine rupture versus failed TOLAC $(p=0.87)$.

Buhimschi et al. retrospectively investigated the uterine rupture localization associated with prostaglandins treatment. Therefore, they compared uterine ruptures during TOLAC in women who received prostaglandins + oxytocin versus uterine ruptures in women with oxytocin alone [30]. The average amount of MVU was 205 (range 160-300) per 10 min in the oxytocin only group compared with 247 (range 140-380) per $10 \mathrm{~min}$ in the prostaglandin/ oxytocin group, during at least $1 \mathrm{~h}$ prior to rupture [30]. These results were not compared with controls.

\section{No change in uterine activity}

Uterine activity patterns of uterine ruptures resulting in permanent severe brain injury have been examined by Phelan et al. [28]. No significant difference in the occurrence of hyperstimulation or tetanic episodes was found. A retrospective study of Menihan et al. focused on both features of fetal heart rates and uterine activity patterns in 11 cases of uterine rupture with $36 \%$ (4/11) IUPC monitoring; no change in uterine activity was found [31]. Leung et al. analyzed uterine activity amongst numerous other features in 86 cases of uterine rupture during TOLAC and observed no decrease of uterine tone or cessation of contractions. Their tocographic method was not described [32]. Finally, Rodriguez et al. also observed no decrease in 39 cases monitored with IUPC [29].

\section{Discussion}

In this systematic review of the literature, several changes in uterine activity have been identified to be associated with uterine rupture: hyperstimulation, decrease in uterine activity, and an increased or reduced baseline tonus. Of these tocogram characteristics, only hyperstimulation could 
be evaluated in a meta-analysis: showing an increased risk of uterine rupture in case of hyperstimulation, on the margin of significance $(p=0.06)$. Furthermore, in a large prospective study, hypertonia was reported in $20 \%$ of the cases and acute absence of contractions in $14 \%$ [10].

We are aware that the majority of the included studies are of retrospective design (12 out of 13). Since uterine rupture is a relatively rare event, retrospective study designs are commonly used. However, this carries the risk of selection bias. For example, Phelan et al. identified their cases within the National Registry of Brain Injured Babies, including only those uterine ruptures resulting in severe perinatal morbidity or 'silent' uterine ruptures potentially leading to selection bias [28]. The size of the retrospective study populations also showed a strong variation, from 9 up to 86 cases of uterine rupture. In addition, the two large retrospective studies showed dissimilar results compared with the single prospective study: Leung et al. $(n=86)$ and Rodriguez et al. $(n=39)$ observed no decrease of uterine activity [29, 32], while Zwart et al. revealed acute absence of contractions in $14 \%$ of uterine rupture cases (25 out of 184) in their prospective study [10]. Furthermore, our systematic search identified multiple large studies regarding uterine ruptures in which information on the tocogram was not provided, which could entail publication bias. For example, Al-Zirqi et al. $(n=94)$ and Kwee et al. $(n=98)$ identified a total of 192 uterine ruptures, yet both studies did not analyze uterine activity patterns [8, 33]. And we excluded the study of Kayani et al., because there was no uterine activity evaluation, while they do report that 'the intrauterine pressure catheters recording have contributed to the diagnosis of uterine rupture' [34].

In this systematic review, we are interested in tocogram characteristics of complete uterine rupture during TOLAC. Uterine rupture concerns a challenging diagnosis. This is reflected in the diverse definitions of uterine rupture in the included studies. A complete uterine rupture, defined as disruption of all the layers of the uterine wall resulting in direct communication between the uterine cavity and peritoneal cavity, might result in different symptoms than dehiscence of the uterine scar, in which case the serosa is still intact leading to minimal intraabdominal bleeding and often few or no symptoms. Several studies identified their cases based on the International Classification of Diseases (ICD-9) coding for uterine rupture during labor, which does not discriminate between a complete rupture and dehiscence [14, 24, 31]. Furthermore, we are aware that not all cases of the included studies concerned women with a previous uterine scar (79-100\%). Finally, uterine activity parameters have not been clarified in some studies. For example, Zwart et al. described hypertonia in $20 \%$ of the uterine rupture cases, but did not define hypertonia [10], whereas studies examining a decrease in uterine activity did not provide a percentage in decrease. Therefore, our systematic review might consist of a mix of both complete and incomplete uterine ruptures, scarred and unscarred uteri, and uterine activity characteristics might be indistinct.

Continuous electronic fetal monitoring is recommended during TOLAC, whilst there is no consensus about the method for monitoring contractions $[12,16]$. International guidelines concerning TOLAC do not recommend routine use of IUPC's as they do not assist in the diagnosis of uterine rupture [12, 16]. Yet, compared with TOCO, an IUPC has the advantage of providing quantitative measurement of uterine resting tone as well as the intensity and MVU of contractions, possibly contributing to the diagnosis of a uterine rupture. Unfortunately, in this systematic review, half of the studies do not document their tocographic method, impeding the comparison of the two modalities used for monitoring uterine contractions. Two features of the tocogram, however, a decrease in contraction amplitude and increasing baseline pressure, are only observed using an IUPC. Rodriguez et al. noticed an increase of baseline uterine tone in 4 out of 39 women monitored IUPC, while not visible in the 29 women monitored with TOCO [29]. This might indicate that an IUPC is needed to observe these subtle changes in the tocogram. The use of IUPC during TOLAC is not supported by Maggio et al. who found no differences in MVU between uterine ruptures and VBAC [35]. Devoe et al. also revealed no change in uterine tone and peak uterine pressure $2.5 \mathrm{~min}$ after uterine incision for CS [36]. Possibly, the observed changes can also be influenced by localization of the catheter [26]. The results of this review do not provide solid evidence for the standard use of an IUPC. Nevertheless, this does not negate the need for adequate uterine monitoring during TOLAC.

The observed association of hyperstimulation and uterine rupture has no trivial relation. The relationship could be causal in nature in the sense that hyperstimulation by oxytocin administration leads to increased stress on the uterine scar and eventually failure. Alternatively, failure of the scar could cause an increase in contraction frequency due to intraabdominal blood causing excitation of the myometrium, in this way preceding a complete rupture. However, based on the physiology of uterine contractions, a decrease rather than an increase in contraction frequency caused by a loss of wall tension is to be expected [18, 37]. The combination is also conceivable and could explain why both changes in contraction frequency were observed: hyperstimulation causing rupture of the scar and then leading to a cessation of uterine contractions. It is remarkable that the only study of ruptures with severe neonatal brain injury showed significant less contractions 
in the uterine rupture group, which might indicate that the disastrous event has already occurred [28]. Finally, it could also be a confounding factor, associated with, for instance, prolonged deliveries, abnormal fetal presentation, or macrosomia. The information available does not permit further analysis of this relationship.

In literature, fetal heart rate abnormality is the most common sign associated with uterine rupture, which has been reported in up to $70 \%$ of the cases of uterine rupture [16]. Andersen et al. even revealed that none of the uterine rupture cases had a completely normal CTG according to the International Federation of Gynecology and Obstetrics (FIGO) guidelines [25]. Only a great number of severe variable decelerations, fetal bradycardia, or preterminal CTG were significant pathologic fetal heart pattern to differentiate uterine rupture from successful VBAC [14, 25]. We calculated the positive predictive values of several fetal heart rate and uterine activity patterns in the study of Ridgeway et al., based on a contingency table and corrected for an estimated uterine rupture prevalence of $1.0 \%$. For example, the estimated positive predictive value for bradycardia in the second stage was $8.3 \%$. In addition, the positive predictive value of mild-moderate and severe variable decelerations in the first stage was, respectively, 1.2 and $4.0 \%$ [14]. Andersen et al. showed comparable low diagnostic values of fetal heart rate characteristics [25]. This compares to the predictive value of uterine hyperstimulation of $4.8 \%$ less than $2 \mathrm{~h}$ prior to delivery evaluated in the study of Pryor et al. [24]. Hence, a pathological CTG cannot be considered as a strong predictor of uterine rupture [25]. Physician decision-making should, therefore, be based on monitoring clinical signs, fetal heart rate patterns, and uterine activity during TOLAC [25].

International guidelines report a two to threefold increased risk of uterine rupture during induction and augmentation of labor [12, 25, 38]. This could be related to the increased risk of uterine hyperstimulation due to oxytocin usage. In the study of Craver Pryor et al., uterine rupture cases experienced a significant longer duration of oxytocin and maximum dose of oxytocin compared with controls [24]. However, no significant differences in oxytocin were reported by Goetzl et al. [23]. These somewhat contradictory results support to at least closely monitor the use of oxytocin to prevent hyperstimulation. Therefore, special attention should be paid to monitor the contraction frequency and to correct the frequency pattern as necessary. Unfortunately, substandard care during TOLAC is a common problem. For example, a proper assessment of the uterine activity could not be made in $28 \%$ of the cases in last hour prior to uterine rupture in the study of Andersen et al. [25]. Moreover, the current guidelines do not recommend a strict contraction frequency. Based on our results, we would advise to aim for
3-5 contractions per $10 \mathrm{~min}$. More than 5 contractions per 10 min should be corrected with oxytocin reduction or tocolytic drugs. And if no adequate tocogram can be obtained with TOCO, alternative tocographic techniques like an IUPC or an EHG-based method should be considered to guarantee adequate uterine monitoring and to prevent hyperstimulation $[39,40]$.

\section{Conclusion}

Uterine rupture can be preceded or accompanied by several types of changes in uterine contractility, including hyperstimulation, reduced number of contractions, increased or reduced baseline tonus. While no typical pattern has been repeatedly reported, we advise close follow-up of uterine contractility for the early detection of atypical changes, and to prevent uterine hyperstimulation.

Acknowledgments The authors acknowledge Ms. Eugenie Delvaux, Librarian at Máxima Medical Center, Veldhoven, The Netherlands, for advice on the systematic electronic search. Furthermore, we thank Birgit van Rijswijk for language editing.

\section{Compliance with ethical standards}

Funding This study was not funded.

Conflict of interest All authors declare that they have no conflict of interest.

Ethical approval This article does not contain any studies with human participants performed by any of the authors. This concerns a systematic review.

Open Access This article is distributed under the terms of the Creative Commons Attribution 4.0 International License (http://crea tivecommons.org/licenses/by/4.0/), which permits unrestricted use, distribution, and reproduction in any medium, provided you give appropriate credit to the original author(s) and the source, provide a link to the Creative Commons license, and indicate if changes were made.

\section{Appendix: Systematic literature searches on September 20th 2016}

Uterine rupture[Mesh] OR uterine rupture[tiab] OR scar rupture[tiab] $=\# 5336$

AND

Labor, Obstetric[Mesh] OR Labor[tiab] OR Trial of labor[Mesh] OR Trial of labor[tiab] OR Trial of labor after cesarean [tiab] OR Vaginal birth after cesarean[Mesh] OR VBAC[tiab] OR uterine scar[tiab] $=\# 91729$

\section{AND}

Uterine contraction[Mesh] OR uterine contraction[tiab] OR contraction*[tiab] OR hyperstimulation[tiab] OR 
uterine monitoring[Mesh] OR uterine monitoring[tiab] OR uterine activity[tiab] OR uterine tone[tiab] OR uterine patterns[tiab] OR Cardiotocography[Mesh] OR cardiotocography[tiab] OR Fetal monitoring[Mesh] OR fetal monitoring [tiab] OR tocogram[tiab] OR external tocodynamometry [tiab] OR intrauterine pressure catheter[tiab] OR intrauterine pressure[tiab] $=\# 148425$

\section{->\# 136 records}

Search EMBASE (uterine rupture OR scar rupture) AND (trail of labor OR obstetric labor OR vaginal birth after cesarean OR VBAC OR uterine scar) AND (uterine contraction OR contraction* OR uterine activity OR cardiotocography OR fetal monitoring OR tocogram OR external tocodynamometry $\mathrm{OR}$ intrauterine pressure) $->\#$ 36 records

Search Cochrane Uterine rupture AND trial of labor AND cardiotocography $->\# 6$ records

\section{References}

1. Betran AP, Merialdi M, Lauer JA, Bing-Shun W, Thomas J, Van Look P, Wagner M (2007) Rates of caesarean section: analysis of global, regional and national estimates. Paediatr Perinat Epidemiol 21(2):98-113. doi:10.1111/j.1365-3016.2007.00786.x

2. Gibbons L, Belizán JM, Lauer JA, Betrán AP, Merialdi M, Althabe F (2010) The global numbers and costs of additionally needed and unnecessary caesarean sections performed per year: Overuse as a barrier to universal coverage. World Health Report 30:1-31

3. Kwee A, Bots ML, Visser GH, Bruinse HW (2007) Obstetric management and outcome of pregnancy in women with a history of caesarean section in the Netherlands. Eur J Obstet Gynecol Reprod Biol 132(2):171-176. doi:10.1016/j.ejogrb.2006.07.017

4. Landon MB, Hauth JC, Leveno KJ, Spong CY, Leindecker S, Varner MW, Moawad AH, Caritis SN, Harper M, Wapner RJ, Sorokin Y, Miodovnik M, Carpenter M, Peaceman AM, O'Sullivan MJ, Sibai B, Langer O, Thorp JM, Ramin SM, Mercer BM, Gabbe SG (2004) Maternal and perinatal outcomes associated with a trial of labor after prior cesarean delivery. N Engl J Med 351(25):2581-2589. doi:10.1056/NEJMoa040405

5. Christmann-Schmid C, Raio L, Scheibner K, Muller M, Surbek D (2016) Back to "once a caesarean: always a caesarean"? A trend analysis in Switzerland. Arch Gynecol Obstet. doi:10.1007/ s00404-016-4055-4

6. Hofmeyr GJ, Say L, Gulmezoglu AM (2005) WHO systematic review of maternal mortality and morbidity: the prevalence of uterine rupture. BJOG 112(9):1221-1228. doi:10.1111/j.14710528.2005.00725.x

7. de Lau H, Gremmels H, Schuitemaker NW, Kwee A (2011) Risk of uterine rupture in women undergoing trial of labour with a history of both a caesarean section and a vaginal delivery. Arch Gynecol Obstet 284(5):1053-1058. doi:10.1007/s00404-0112048-x

8. Kwee A, Bots ML, Visser GH, Bruinse HW (2006) Uterine rupture and its complications in the Netherlands: a prospective study. Eur J Obstet Gynecol Reprod Biol 128(1-2):257-261. doi:10.1016/j.ejogrb.2006.02.005

9. Landon MB, Leindecker S, Spong CY, Hauth JC, Bloom S, Varner MW, Moawad AH, Caritis SN, Harper M, Wapner RJ,
Sorokin Y, Miodovnik M, Carpenter M, Peaceman AM, O'Sullivan MJ, Sibai BM, Langer O, Thorp JM, Ramin SM, Mercer BM, Gabbe SG (2005) The MFMU Cesarean Registry: factors affecting the success of trial of labor after previous cesarean delivery. Am J Obstet Gynecol 193(3 Pt 2):1016-1023. doi:10. 1016/j.ajog.2005.05.066

10. Zwart JJ, Richters JM, Ory F, de Vries JI, Bloemenkamp KW, van Roosmalen J (2009) Uterine rupture in The Netherlands: a nationwide population-based cohort study. BJOG 116(8):1069-1078. doi:10.1111/j.1471-0528.2009.02136.x (discussion 1078-1080)

11. Guise JM, McDonagh MS, Osterweil P, Nygren P, Chan BK, Helfand M (2004) Systematic review of the incidence and consequences of uterine rupture in women with previous caesarean section. BMJ 329(7456):19-25. doi:10.1136/bmj.329.7456.19

12. RCOG Guideline: Birth after previous caesarean birth (2007). Royal College of Obstetricians and Gynaecologists Londen, UK

13. Ayres AW, Johnson TR, Hayashi R (2001) Characteristics of fetal heart rate tracings prior to uterine rupture. Int $\mathrm{J}$ Gynaecol Obstet 74(3):235-240

14. Ridgeway JJ, Weyrich DL, Benedetti TJ (2004) Fetal heart rate changes associated with uterine rupture. Obstet Gynecol 103(3):506-512. doi:10.1097/01.AOG.0000113619.67704.99

15. Tutschek B, Bender HG, Henrich W (2005) Silent uterine rupture during vaginal delivery successfully managed conservatively. Ultrasound Obstet Gynecol 26(2):199-200. doi:10.1002/uog.1931

16. ACOG Practice bulletin no. 115: (2010) Vaginal birth after previous cesarean delivery. Obstet Gynecol 116(2 Pt 1):450-463. doi:10.1097/AOG.0b013e3181eeb251

17. Gee H, Taylor EW, Hancox R (1988) A model for the generation of intra-uterine pressure in the human parturient uterus which demonstrates the critical role of the cervix. J Theor Biol 133(3):281-291

18. Young RC, Goloman G (2011) Mechanotransduction in rat myometrium: coordination of contractions of electrically and chemically isolated tissues. Reprod Sci 18(1):64-69. doi:10.1177/ 1933719110379637

19. de Lau H, Yang KT, Rabotti C, Vlemminx M, Bajlekov G, Mischi M, Oei SG (2016) Toward a new modality for detecting a uterine rupture: electrohysterogram propagation analysis during trial of labor after cesarean. J Matern Fetal Neonatal Med:1-6. doi:10.1080/14767058.2016.1178227

20. Sheiner E, Levy A, Ofir K, Hadar A, Shoham-Vardi I, Hallak M, Katz M, Mazor M (2004) Changes in fetal heart rate and uterine patterns associated with uterine rupture. J Reprod Med 49(5):373-378

21. Chen KC, Hsieh TT (1992) Rupture of gravid uterus: a 8-year clinical analysis and review of the literature. Changgeng Yi Xue Za Zhi 15(1):15-22

22. Wells GA, Shea B, O'Connell D, Peterson J, Welch V, Losos M, Tugwell P The Newcastle-Ottawa Scale (NOS) for assessing the quality of nonrandomised studies in meta-analyses. http://www. ohri.ca/programs/clinical_epidemiology/oxford.asp. Accessed September 25th 2016

23. Goetzl L, Shipp TD, Cohen A, Zelop CM, Repke JT, Lieberman E (2001) Oxytocin dose and the risk of uterine rupture in trial of labor after cesarean. Obstet Gynecol 97(3):381-384

24. Craver Pryor E, Mertz HL, Beaver BW, Koontz G, MartinezBorges A, Smith JG, Merrill D (2007) Intrapartum predictors of uterine rupture. Am J Perinatol 24(5):317-321. doi:10.1055/s2007-981433

25. Andersen MM, Thisted DL, Amer-Wahlin I, Krebs L (2016) Can intrapartum cardiotocography predict uterine rupture among women with prior caesarean delivery? A population based casecontrol study. PLoS One 11(2):e0146347. doi:10.1371/journal. pone. 0146347 
26. Arulkumaran S, Chua S, Ratnam SS (1992) Symptoms and signs with scar rupture-value of uterine activity measurements. Aust N Z J Obstet Gynaecol 32(3):208-212

27. Beckley S, Gee H, Newton JR (1991) Scar rupture in labour after previous lower uterine segment caesarean section: the role of uterine activity measurement. Br J Obstet Gynaecol 98(3):265-269

28. Phelan JP, Korst LM, Settles DK (1998) Uterine activity patterns in uterine rupture: a case-control study. Obstet Gynecol 92(3):394-397

29. Rodriguez MH, Masaki DI, Phelan JP, Diaz FG (1989) Uterine rupture: are intrauterine pressure catheters useful in the diagnosis? Am J Obstet Gynecol 161(3):666-669

30. Buhimschi CS, Buhimschi IA, Patel S, Malinow AM, Weiner CP (2005) Rupture of the uterine scar during term labour: contractility or biochemistry? BJOG 112(1):38-42. doi:10.1111/j.14710528.2004.00300.x

31. Menihan CA (1998) Uterine rupture in women attempting a vaginal birth following prior cesarean birth. J Perinatol $18(6 \mathrm{Pt}$ 1):440-443

32. Leung AS, Leung EK, Paul RH (1993) Uterine rupture after previous cesarean delivery: maternal and fetal consequences. Am J Obstet Gynecol 169(4):945-950

33. Al-Zirqi I, Stray-Pedersen B, Forsen L, Vangen S (2010) Uterine rupture after previous caesarean section. BJOG 117(7):809-820. doi:10.1111/j.1471-0528.2010.02533.x
34. Kayani SI, Alfirevic Z (2005) Uterine rupture after induction of labour in women with previous caesarean section. BJOG 112(4):451-455. doi:10.1111/j.1471-0528.2004.00336.x

35. Maggio L, Forbes J, Carey LL, Sangi-Haghpeykar H, Davidson C (2014) Association of Montevideo units with uterine rupture in women undergoing a trial of labor. J Reprod Med 59(9-10): 464-470

36. Devoe LD, Croom CS, Youssef AA, Murray C (1992) The prediction of "controlled" uterine rupture by the use of intrauterine pressure catheters. Obstet Gynecol 80(4):626-629

37. Lammers WJ (2012) The electrical activities of the uterus during pregnancy. Reprod Sci. doi:10.1177/1933719112446082

38. Rossi AC, Prefumo F (2015) Pregnancy outcomes of induced labor in women with previous cesarean section: a systematic review and meta-analysis. Arch Gynecol Obstet 291(2):273-280. doi:10.1007/s00404-014-3444-9

39. Euliano TY, Nguyen MT, Darmanjian S, McGorray SP, Euliano N, Onkala A, Gregg AR (2013) Monitoring uterine activity during labor: a comparison of 3 methods. Am J Obstet Gynecol 208(1):66 e61-66 e66. doi:10.1016/j.ajog.2012.10.873

40. Vlemminx MW, de Lau H, Vullings R, Peters CH, Oei SG (2015) Electrohysterography. A promising alternative for monitoring contractions. Ned Tijdschr Geneeskd 159:A8535 